\title{
Physiological and Biochemical Effects of Klebsiella oxytoca Infection on Model Organism Galleria mellonella L.
}

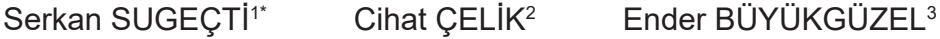 \\ Kemal BÜYÜKGÜZEL ${ }^{4}$ \\ 'Zonguldak Bülent Ecevit University, Çaycuma Food and Agriculture \\ Vocational School, Department of Veterinary Medicine, Zonguldak, TURKEY \\ ${ }^{2}$ Zonguldak Bülent Ecevit University, Çaycuma Food and Agriculture Vocational \\ School, Department of Laboratory Technology, Zonguldak, TURKEY \\ ${ }^{3}$ Zonguldak Bülent Ecevit University, Science and Art Faculty, \\ Department of Molecular Biology and Genetics, Zonguldak, TURKEY \\ ${ }^{4}$ Zonguldak Bülent Ecevit University, Science and Art \\ Faculty, Department of Biology, Zonguldak, TURKEY \\ e-mails: ${ }^{1 *}$ serkan.sugecti@hotmail.com, ${ }^{2}$ cihat.celik@beun.edu.tr, \\ 3endericen@hotmail.com, ${ }^{4}$ buyukguzelk@hotmail.com \\ ORCID IDs: ${ }^{10000-0003-3412-2367, ~}{ }^{20000-0002-2400-3412, ~}{ }^{30000-0002-4442-5081, ~}$ \\ ${ }^{4} 0000-0002-9589-9383$
}

\begin{abstract}
In this study, the physiological and biochemical response of model insect Galleria mellonella due to Klebsiella oxytoca infection was investigated. Changes in metabolic enzyme activities such as aspartate transferase (AST), alanine transferase (ALT), alkaline phosphatase (ALP), amylase (AMYL) and gamma glutamyl transferase (GGT) occurred due to $K$. oxytoca infection. In addition, amounts of non-enzymatic antioxidant such as uric acid (UA), bilirubin (BIL) and albumin (ALB) were altered in G. mellonella hemolymph due to infection. The results obtained from this study showed that $G$. mellonella can be used as a model organism in the evaluation of the physiological effects of $K$. oxytoca infection on the host.
\end{abstract}

Key words: Galleria mellonella, model insect, antioxidant responses, infection.

Sugeçti, S., Çelik, C., Büyükgüzel, E., \& Büyükgüzel, K. (2021). Physiological and biochemical effects of Klebsiella oxytoca infection on model organism Galleria mellonella L. Journal of the Entomological Research Society, 23(3), 279-286. 


\section{INTRODUCTION}

Klebsiella species are nosocomial pathogens with high virulence. Although they usually infect immunocompromised individuals, these isolates make treatment difficult because they are resistant to many antibiotics (Bassetti et al, 2018; Rønning et al, 2019). Klebsiella oxytoca is a gram-negative bacteria associated with nosocomial infections. In recent years, the high resistance of $K$. oxytoca against antibiotics used especially in urinary tract infections has increased the interest of researchers in this pathogen (Tominaga 2018; Hu, Wei, Feng, Xie, \& Zong, 2019).

In recent years, invertebrate experimental animals have been used to study bacterial infection and host interactions (Shaik, Mishra, Sehadová, \& Kodrík, 2020; Lapointe, McCarthy, Dunphy, \& Mandato, 2020). In addition, invertebrate infection models are frequently used in the fields of medicine, pharmacy and veterinary medicine (Matsumoto, Ishii, Shimizu, Kawamoto, \& Sekimizu, 2017; Ishii, Matsumoto, Yamada, Abe, \& Sekimizu, 2017; Singulani, Scorzoni, De Oliveira, Marcos, \& Assato, 2018). In particular, Galleria mellonella (Lepidoptera: Pyralidae) larvae have been used as model organisms in many studies on bacterial pathogenicity or the efficacy of antibiotic treatments (Rossoni et al, 2017; Shaik et al, 2020; Lapointe, McCarthy, Dunphy, \& Mandato, 2020). The large surface area of G. mellonella larvae and the easy isolation of hemolymph provide advantages for physiological and biochemical studies (Andrejko, Zdybicka-Barabas, \& Cytryńska, 2014; Tsai, Loh, \& Proft, 2016).

Many studies have reported that biological and chemical agents negatively affect metabolic and immune responses in insects (Sugeçti, Büyükgüzel, \& Büyükgüzel, 2016; Kastamonuluoğlu, Büyükgüzel, \& Büyükgüzel, 2020). Aspartate transferase (AST) and alanine transferase (ALT) activities significantly increase in insects, especially in cellular damage due to oxidative stress (Sertçelik, Sugeçti, Büyükgüzel, Necefoğlu, \& Büyükgüzel, 2018). On the other hand, alkaline phosphatase (ALP) and amylase (AMYL) activities have important roles in regulating energy metabolism in insects against oxidative damage (Sugeçti \& Büyükgüzel, 2018). The other metabolic enzyme, gamma glutamyl transferase (GGT), increases the availability of amino acids, mainly cysteine, for intracellular glutathione synthesis and plays an important role in maintaining non-enzymatic antioxidant defense against oxidative stress in organisms (Ndrepepa, Colleran, \& Kastrati, 2018). In addition, oxidative damage to insect tissues is prevented by enzymatic such as superoxide dismutase (SOD), glutathione peroxidase (GPx) and catalase (CAT) and non-enzymatic antioxidants such as amount of uric acid (UA), bilirubin (BIL) and albumin (ALB) (Mirończuk-Chodakowska, Witkowska, \& Zujko, 2018; Alp \& Coskun 2018). It is known that biochemical parameters such as total protein (TP) and urea are negatively affected as a result of oxidative damage in insects (Etebari, Bizhannia, Sorati, \& Matindoost, 2007; Sertçelik et al, 2018).

In this study, the changes in the activity of metabolic enzymes such as AST, ALT, ALP, AMYL, GGT and amount of biochemical parameters such as ALB, BILD, BILT, TP, UA and UREA in hemolymph of $G$. mellonella larvae after infection with $K$. oxytoca were investigated. 
The Effects of Klebsiella oxytoca Infection on Model Organism Galleria mellonella

\section{MATERIALS AND METHODS}

\section{Insect culture}

G. mellonella culture was obtained from the Insect Culture Laboratory in Biology department of Zonguldak Bülent Ecevit University. Insect culture was continued in an incubator set at $28 \pm 2{ }^{\circ} \mathrm{C}$ and $65 \pm 5 \%$ humidity under laboratory conditions. Insects were reared in artificial diet until the seventh larval stage of G. mellonella. Artificial diet was composed of $420 \mathrm{~g}$ of bran, $150 \mathrm{ml}$ of filtered honey, $150 \mathrm{ml}$ of glycerol, 20 $\mathrm{g}$ of ground old dark honeycomb, and $30 \mathrm{ml}$ of distilled water (Bronskill, 1961).

\section{Experimental design}

K. oxytoca (ATCC 8724) was obtained from local company. K. oxytoca was prepared in a brain heart solution according to the $0.5 \mathrm{McF}$ arland standard. The solution $(10 \mu \mathrm{l})$ prepared according to this standard (about $1 \times 10^{7}$ bacteria) was injected through the abdomen of the insect. Hemolymph was collected at 2, 4, 6 and 8 hours after injection. As the control group, only $10 \mu \mathrm{l}$ brain heart solution was injected and hemolymph was collected 8 hours after the injection. Before the hemolymph was collected, the larvae were kept on ice for about 5 minutes and their surfaces were disinfected with ethyl alcohol. Samples were stored at $-80^{\circ} \mathrm{C}$ until analyses. The experiments were repeated four times.

\section{Biochemical analysis}

The collected hemolymph was placed in homogenization buffer (w/v 1.15\% potassium chloride $(\mathrm{KCl}), 25 \mathrm{mM}$ dipotassium hydrogen phosphate $\left(\mathrm{K}_{2} \mathrm{HPO}_{4}\right), 5 \mathrm{mM}$ ethylen-diaminetetraacetic acid (EDTA), $2 \mathrm{mM}$ phenylmethylsulphonil fluoride (PMSF), $2 \mathrm{mM}$ dithiothreitol (DTT), $\mathrm{pH}$ 7.0). Extracts of hemolymph were prepared at $4^{\circ} \mathrm{C}$ by an ultrasonic homogenizer (Bandelin Sonoplus, HD2070, Germany). Then, solution was centrifuged at $10.000 \mathrm{~g}$ for $10 \mathrm{~min}$ at $4^{\circ} \mathrm{C}$. The analyses were performed with the Roche Hitachi Cobas c501 instrument (Roche, Germany) using appropriate kits. ALT (Kit no: 46051001), AST (Kit no: 46004201), GGT (Kit no: 44686801), ALP (Kit No: 44211201), AMYL (Kit No: 45142401). ALB (Kit no: 44430501), BILD (Kit no: 46042501), BILT (Kit no: 43808801), UA (Kit no: 44535001), TP (Kit no: 44686201) and UREA (Kit no: 45141501).

\section{Statistical analysis}

A one-way analysis of variance (ANOVA) was used to analyze data on cell damage indicators, metabolic enzymes non-enzymatic antioxidants and biochemical parameters of G. mellonella. Tukey's HSD test was used to determine the significance of the difference between the mean. All analyses were performed in SPSS v.15.0 (SPSS, Chicago, IL, USA). A probability level of 0.05 was used to check the significance of the difference between the averages. (SPSS, 2006). 
SUGEÇTI, S., ÇELIK, C., BÜYÜKGÜZEL, E., BÜYÜKGÜZEL, K.

\section{RESULTS}

\section{Effect of $K$. oxytoca infection on metabolic enzymes activities in hemolymph of $G$. mellonella larvae}

In the present study, AST activity statistically increased 8 hours after with $K$. oxytoca infection when compared the control group $\left(F_{4.15}: 311.346, p<0.05\right)$. Similarly, ALT activity significantly increased in hemolymph of $G$. mellonella larvae at 8 hours after injection $\left(F_{4,15}: 229.497, p<0.05\right)$. ALP activity decreased approximately 3 -fold 8 hours after injection when compared to the control group $\left(\mathrm{F}_{4,15}: 16.545, \mathrm{p}<0.05\right)$. AMYL activity significantly decreased from $12.75 \mathrm{U} / \mathrm{L}$ to $13.75 \mathrm{U} / \mathrm{L} 8$ hours after with $\mathrm{K}$. oxytoca infection $\left(\mathrm{F}_{4,15}: 227.019, \mathrm{p}<0.05\right)$. Other metabolic enzyme GGT activity was statistically increased 8 hours after exposure to K. oxytoca $\left(F_{4,15}: 24.468, p<0.05\right)$ (Table 1$)$.

Table 1. Effect of $K$. oxytoca infection on metabolic enzymes activities in hemolymph of $G$. mellonella larvae.

\begin{tabular}{|c|c|c|c|c|c|}
\hline Time & $\begin{array}{c}\text { AST } \\
(U / L) \\
(\text { Mean } \pm S . E)^{\dagger}\end{array}$ & $\begin{array}{c}\text { ALT } \\
(\mathrm{U} / \mathrm{L}) \\
(\text { Mean } \pm \text { S.E } E)^{\dagger}\end{array}$ & $\begin{array}{c}\text { ALP } \\
(\mathrm{U} / \mathrm{L}) \\
(\text { Mean } \pm \text { S.E })^{\dagger}\end{array}$ & $\begin{array}{c}\text { AMYL } \\
(\mathrm{U} / \mathrm{L}) \\
\left(\text { Mean } \pm \text { S.E }^{\dagger}\right.\end{array}$ & $\begin{array}{c}\text { GGT } \\
(\mathrm{U} / \mathrm{L}) \\
\left(\mathrm{Mean}^{*} \pm\right. \\
\text { S.E })^{\dagger}\end{array}$ \\
\hline Control & $59.25 \pm 4.42 \mathrm{a}$ & $9.50 \pm 0.75 a$ & $9.75 \pm 0.64 a$ & $12.75 \pm 5.23 a$ & $4.27 \pm 1.10 \mathrm{a}$ \\
\hline 2 & $68.50 \pm 7.29 a$ & $30.50 \pm 2.94 b$ & $4.85 \pm 0.82 b$ & $12.50 \pm 0.43 a$ & $2.55 \pm 0.51 a$ \\
\hline 4 & $58.50 \pm 9.83 a$ & $33.50 \pm 6.17 b$ & $5.00 \pm 1.11 b$ & $95.00 \pm 2.69 b$ & $2.75 \pm 0.32 a$ \\
\hline 6 & $55.00 \pm 0.50 a$ & $72.50 \pm 6.72 c$ & $1.15 \pm 0.14 c$ & $29.75 \pm 1.90 c$ & $2.00 \pm 0.22 a$ \\
\hline 8 & $333.01 \pm 2.59 b$ & $217.01 \pm 4.55 d$ & $3.30 \pm 0.38 b c$ & $13.75 \pm 0.86 \mathrm{ad}$ & $14.9 \pm 2.21 b$ \\
\hline
\end{tabular}

* Mean of four replicates per treatment with 20 larvae per replicate

† Means within a column followed by the same lowercase letter are not significantly different (Tukey's HSD test: $p>0.05$ )

$\gamma$ Control: 8 hours after brain-heart solution injection.

\section{Effect of $K$. oxytoca infection on biochemical parameters in hemolymph of $G$. mellonella larvae}

The amount of ALB decreased approximately 4 -fold 8 hours after K. oxytoca infection $\left(\mathrm{F}_{4,15}: 58.160, \mathrm{p}<0.05\right)$. The amount of BILD increased from $0.29 \pm 0.02$ $\mathrm{mg} / \mathrm{dL}$ to $0.48 \pm 0.05 \mathrm{mg} / \mathrm{dL} 8$ hours after infection. However, this increase in the amount of BILD was not statistically significant $\left(F_{4,15}: 3.153, p>0.05\right)$. The amount of BILT increased statistically 8 hours after $K$. oxytoca infection $\left(F_{4.15}: 4.137, p<0.05\right)$. The amount of TP in hemolymph of $G$. mellonella larvae significantly decreased 8 hours after infection $\left(F_{4,15}: 90.254, p<0.05\right)$. The amount of $U A$ decreased from $0.58 \pm$ $0.01 \mathrm{mg} / \mathrm{dL}$ to $0.26 \pm 0.05 \mathrm{mg} / \mathrm{dL} 8$ hours $K$. oxytoca infection $\left(\mathrm{F}_{4.15}: 6.852, \mathrm{p}<0.05\right)$. The amount of UREA increased approximately 8 -fold 8 hours after with $K$. oxytoca infection when compered the control group $\left(F_{4,15}: 13.461, p<0.05\right)$. (Table 2).

\section{DISCUSSION}

In this study, the pathophysiological effects of the pathogen $K$. oxytoca on the invertebrate model organism G. mellonella were investigated. Biochemical parameters in 


\section{The Effects of Klebsiella oxytoca Infection on Model Organism Galleria mellonella}

hemolymph of G. mellonella were affected negatively. In addition, changes in the amount of non-enzymatic antioxidants occurred in G. mellonella hemolymph due to the infection.

Table 2. Effect of $K$. oxytoca infection on biochemical parameters in hemolymph of $G$. mellonella larvae.

\begin{tabular}{|c|c|c|c|c|c|c|}
\hline Time & $\begin{array}{c}\text { ALB } \\
(\mathrm{g} / \mathrm{dL}) \\
(\mathrm{Mean} \pm \mathrm{S} . \mathrm{E})^{\dagger}\end{array}$ & $\begin{array}{c}\mathrm{BILD} \\
(\mathrm{mg} / \mathrm{dL}) \\
(\mathrm{Mean} \pm \\
\mathrm{S} . \mathrm{E})^{\dagger}\end{array}$ & $\begin{array}{c}\mathrm{BILT} \\
(\mathrm{mg} / \mathrm{dL}) \\
\left(\mathrm{Mean}^{*} \pm\right. \\
\mathrm{S} . \mathrm{E})^{\dagger}\end{array}$ & $\begin{array}{c}\mathrm{TP} \\
(\mathrm{g} / \mathrm{dL}) \\
\left(\mathrm{Mean}^{*} \pm \mathrm{S} . \mathrm{E}\right)^{\dagger}\end{array}$ & $\begin{array}{c}\text { UA } \\
(\mathrm{mg} / \mathrm{dL}) \\
(\mathrm{Mean} \pm \\
\text { S.E })^{\dagger}\end{array}$ & $\begin{array}{c}\text { UREA } \\
(\mathrm{mg} / \mathrm{dL}) \\
\left(\mathrm{Mean}^{*} \pm \mathrm{S} . \mathrm{E}\right)^{\dagger}\end{array}$ \\
\hline Control $^{*}$ & $2.15 \pm 0.11 \mathrm{a}$ & $0.29 \pm 0.02 \mathrm{a}$ & $0.39 \pm 0.02 \mathrm{a}$ & $6.72 \pm 0.25 \mathrm{a}$ & $0.58 \pm 0.01 \mathrm{a}$ & $2.55 \pm 0.50 \mathrm{a}$ \\
\hline 2 & $1.55 \pm 0.12 \mathrm{~b}$ & $0.41 \pm 0.09 \mathrm{a}$ & $0.62 \pm 0.12 \mathrm{~b}$ & $4.71 \pm 0.41 \mathrm{~b}$ & $0.64 \pm 0.04 \mathrm{a}$ & $16.20 \pm 1.55 \mathrm{~b}$ \\
\hline 4 & $1.85 \pm 0.04 \mathrm{ab}$ & $0.66 \pm 0.15 \mathrm{~b}$ & $1.07 \pm 0.25 \mathrm{c}$ & $5.49 \pm 0.08 \mathrm{~b}$ & $0.77 \pm 0.15 \mathrm{a}$ & $12.86 \pm 3.22 \mathrm{~b}$ \\
\hline 6 & $0.51 \pm 0.05 \mathrm{c}$ & $0.16 \pm 0.03 \mathrm{c}$ & $0.25 \pm 0.03 \mathrm{a}$ & $1.35 \pm 0.02 \mathrm{c}$ & $0.25 \pm 0.02 \mathrm{ab}$ & $5.05 \pm 0.28 \mathrm{a}$ \\
\hline 8 & $0.50 \pm 0.08 \mathrm{c}$ & $0.48 \pm 0.05 \mathrm{a}$ & $0.71 \pm 0.04 \mathrm{~b}$ & $1.42 \pm 0.015 \mathrm{c}$ & $0.26 \pm 0.05 \mathrm{ab}$ & $18.30 \pm 1.19 \mathrm{~b}$ \\
\hline
\end{tabular}

Mean of four replicates per treatment with 20 larvae per replicate

† Means within a column followed by the same lowercase letter are not significantly different (Tukey's

HSD test: $p>0.05$ )

$\gamma$ Control: 8 hours after brain-heart solution injection

Biological and chemical agents are known to disrupt the energy metabolism of insects, cause cell damage and alter the antioxidant system (İçen, Armutçu, Büyükgüzel, \& Gürel, 2005; Sertçelik et al, 2018; Sugeçti \& Büyükgüzel, 2018; Farahani, Bandani, Alizadeh, Goldansaz, \& Whyard, 2020). In this study, it was determined that the cell damage indicators AST and ALT enzyme activities were increased in the hemolymph of G. mellonella larvae exposed to K. oxytoca for 8 hours. The reason for this increase may be cell damage due to the high virulence effect of the bacteria. In addition, ALP activity from metabolic enzymes was found to be decreased 8 hours after injection. The reason for this reduces may be increased oxidative damage due to the pathogenic effect of the bacteria. Studies have reported that ALP activity increases in insect tissues to regulate energy metabolism, which is disrupted by oxidative damage (Etebari et al, 2007; Sertçelik et al, 2018). In this study, it was determined that other metabolic GGT activity increased 8 hours after injection. GGT is an important metabolic enzyme that catalyzes the extracellular degradation of glutathione by hydrolyzing cysteine and y glutamyl bond extracellularly. The amount of cysteine and glutamyl enters the cell and the synthesis of glutathione, an important antioxidant, increases (Sugeçti \& Büyükgüzel, 2018). In this study, the increase in GGT activity may be physiological adaptation to increase the insect's antioxidant defense system. In another study, the physiological effects of an anthelmintic drug, oxfendazole, on the hemolymph of G. mellonella larvae were investigated. It has been determined that oxfendazole significantly increases the activity of cell damage indicators AST and ALT and the metabolic enzymes ALP, AMYL, CK and GGT (Sugeçti and Büyükgüzel 2018). In another study with similar results, the metal complex was injected into $G$. mellonella larvae and changes in metabolic enzymes activities were investigated. AST, ALT, LDH, CK, ALP and GGT activity increased significantly in the hemolymph of G. mellonella larvae 8 hours after injection of the metal complex (Sertçelik et al, 2018). In another study, transferase enzymes such as AST, ALT and GGT were increased in the hemolymph of great wax moth larvae due to E.coli infection (Sugeçti, 2021a). 
Grizanova, Krytsyna, Surcova, \& Dubovskiy (2019) reported that esterase activity was significantly reduced in $\mathrm{G}$. mellonella midgut tissue due to Bacillus thuringiensis infection (Grizanova, Krytsyna, Surcova, \& Dubovskiy, 2019). Wand, McCowen, Nugent, \& Sutton (2013) reported that due to K. pneumoniae infection, LDH enzyme activity (cell damage indicator) increased in hemolymph of G. mellonella larvae and cell damage occurred (Wand, McCowen, Nugent, \& Sutton, 2013). In another study, it was reported that cell damage was increased in $G$. mellonella larvae due to $K$. pneumoniae infection. It was determined that AST, ALT and LDH activities increased due to K. pneumoniae infection, and AMYL, ALP and CK enzyme activities also increased for the regulation of energy metabolism (Sugeçti, 2021b). These studies on the same insect show that biological and chemical agents increase the insect's metabolic enzymes and support our study.

Insects protect themselves against chemicals, especially insecticides and pathogenic bacteria infections with their antioxidant defense system (Dubovskii et al, 2010; Çelik \& Sak, 2020). Antioxidant defense system is provided with enzymatic antioxidants such as CAT, SOD and GPx or non-enzymatic antioxidants such as ALB, UA and BIL. In this study, 8 hours after K. oxytoca injection, it was determined that the amount of non-enzymatic antioxidants BILT significantly increased. This increase may be due to adaptation to the oxidative damage caused by the pathogen. The amount of ALB and UA significantly decreased due to the infection. It has been reported in various studies that antioxidative levels increase in insects against the oxidative effects of pathogenic bacteria. In another study, it was reported that $G$. mellonella antioxidant effect increased due to Bacillus thuringiensis infection (Dubovskii et al, 2010). In another study, antioxidant enzymes such as SOD and GST levels were increased in G. mellonella larvae after infection with $B$. thuringiensis (Dubovskii, Olifirenko, \& Glupov, 2005). Altuntaş \& Duman (2017) reported that the antioxidant response in hemolymph of $G$. mellonella larvae to the entomopathogenic fungus Purpureocillium lilacinus infection altered as a physiological adaptation (Altuntaş \& Duman 2017).

In this study, the amount of UREA in hemolymph of G. mellonella larvae significantly increased depending on the exposure time to the pathogen. The amount of TP decreased significantly due to $K$. oxytoca infection. It is known that especially the amount of protein increases in the regulation of energy metabolism against oxidative damage (Sertçelik et al, 2018; Çelik, Büyükgüzel, \& Büyükgüzel, 2019). In this study, the reason for the decrease in the amount of TP may be damage due to infection. In particular, the increase in cell damage indicators AST and ALT activities supported this hypothesis. In a study, it has been reported that the chemical agent terbinafine $(0.1 \%)$ increased protein oxidation and causes protein damage in the midgut of $G$. mellonella larvae (Kastamonuluoğlu, Büyükgüzel, \& Büyükgüzel, 2020). In another study, it was reported that the amount of TP increased in G. mellonella larvae exposed to different concentrations $(0.003,0.03$ and $0.3 \%$ ) of oxyclozanide (Çelik, Büyükgüzel, \& Büyükgüzel, 2019). Etebari et al (2007) reported that the amount of TP and UREA in Bombyx mori L. (Lepidoptera: Bombycidae) larvae exposed to pyriproxyfen increased after 120 hours (Etebari et al, 2007). In another study, it was reported that biochemical parameters such as TP, UREA, cholesterol, ions and amount of non-enzymatic 
The Effects of Klebsiella oxytoca Infection on Model Organism Galleria mellonella

antioxidants such as ALB, BIL and UA were altered due to 8 hours after $K$. pneumoniae infection in the hemolymph of last instar G. mellonella larvae (Sugeçti, 2021b).

The results obtained from this study showed that $G$. mellonella can be used as a model organism in the evaluation of the physiological effects of $K$. oxytoca infection on the host. As a result, this study showed that G. mellonella is an important experimental model in the investigation of biochemical interaction between pathogenic bacteria and host.

\section{REFERENCES}

Alp, E. \& Coskun, M. (2018). Effects of the organophosphate insecticide fenthion on the antioxidant defense system and lipid peroxidation of Galleria mellonella L. Fresenius Environmental Bulletin 27, 8280-8285.

Altuntaş, H. \& Duman, E. (2017). Toxicological effects of the entomopathogenic Purpureocillium lilacinus on the model organism, Galleria mellonella. Biological Diversity and Conservation, 10(1), 153-159.

Andrejko, M., Zdybicka-Barabas, A., \& Cytryńska, M. (2014). Diverse effects of Galleria mellonella infection with entomopathogenic and clinical strains of Pseudomonas aeruginosa. Journal of Invertebrate Pathology, 115, 14-25.

Bassetti, M., Giacobbe D.R., Giamarellou, H., Viscoli, C., Daikos, G.L., Dimopoulos, G., \& Karaiskos, I. (2018). Management of KPC-producing Klebsiella pneumoniae infections. Clinical Microbiology and Infection, 24, 133-144.

Bronskill, J. (1961). A cage to simplify the rearing of the greater wax moth, Galleria mellonella (Pyralidae), Journal of the Lepidopterists' Society, 15, 102-104.

Çelik, C., Büyükgüzel, K., \& Büyükgüzel, E. (2019). The effects of oxyclozanide on survival, development and total protein of Galleria mellonella L. (Lepidoptera: Pyralidae), Journal of the Entomological Research Society, 21, 95-108.

Çelik, E. \& Sak, O. (2020). Effects of kinetin on biological parameters and hemocytes of Achroia grisella (Lepidoptera: Pyralidae). Archives of Biological Sciences, 72, 181-192.

Dubovskii, I. M., Olifirenko, O. A., \& Glupov, V. V. (2005). Level and activities of antioxidants in intestine of larvae Galleria mellonella L. (Lepidoptera, Pyralidae) at peroral infestation by bacteria Bacillus thuringiensis ssp. galleriae. Journal of Evolutionary Biochemistry and Physiology, 41, 20-25.

Dubovskii, I.M., Grizanova, E.V., Chertkova, E.A., Slepneva, I.A., Komarov, D.A., Vorontsova, Y.L., \& Glupov, V.V. (2010). Generation of reactive oxygen species and activity of antioxidants in hemolymph of the moth larvae Galleria mellonella (L.) (Lepidoptera: Piralidae) at development of the process of encapsulation. Journal of Evolutionary Biochemistry and Physiology, 46, 35-43.

Etebari, K., Bizhannia, A.R., Sorati, R., \& Matindoost, L. (2007). Biochemical changes in haemolymph of silkworm larvae due to pyriproxyfen residue. Pesticide Biochemistry and Physiology, 88, 14-19.

Farahani, S., Bandani, A.R., Alizadeh, H., Goldansaz, S.H., \& Whyard, S. (2020). Differential expression of heat shock proteins and antioxidant enzymes in response to temperature, starvation, and parasitism in the Carob moth larvae, Ectomyelois ceratoniae (Lepidoptera: Pyralidae), PloS One, 15, e0228104.

Grizanova, E. V., Krytsyna, T. I., Surcova, V. S., \& Dubovskiy, I. M. (2019). The role of midgut nonspecific esterase in the susceptibility of Galleria mellonella larvae to Bacillus thuringiensis. Journal of Invertebrate Pathology, 166, 107208.

Hu, Y., Wei, L., Feng, Y., Xie, Y., \& Zong, Z. (2019). Klebsiella huaxiensis sp. nov., recovered from human urine. International Journal of Systematic and Evolutionary Microbiology, 69, 333-336.

İçen, E., Armutçu, F., Büyükgüzel, K., \& Gürel, A. (2005). Biochemical stress indicators of greater wax moth exposure to organophosphorus insecticides. Journal of Economic Entomology, 98, 358-366.

Ishii, M., Matsumoto, Y., Yamada, T., Abe, S., \& Sekimizu K. (2017). An invertebrate infection model for evaluating anti-fungal agents against dermatophytosis, Scientific Reports, 7, 1-11.

Kastamonuluoğlu, S., Büyükgüzel, K., \& Büyükgüzel, E. (2020). The use of dietary antifungal agent terbinafine in artificial diet and its effects on some biological and biochemical parameters of the model organism Galleria mellonella (Lepidoptera: Pyralidae). Journal of Economic Entomology, 113, 1110-1117. 
Lapointe, J.F., McCarthy, C.D., Dunphy, G.B., \& Mandato, C.A. (2020). Physiological evidence of integrin-antibody reactive proteins influencing the innate cellular immune responses of larval Galleria mellonella hemocytes. Insect Science, 27, 239-255.

Matsumoto, Y., Ishii, M., Shimizu, K., Kawamoto, S., \& Sekimizu, K. (2017). A silkworm infection model to evaluate antifungal drugs for cryptococcosis, Medical Mycology Journal, 58, 131-137.

Mirończuk-Chodakowska, I., Witkowska, A.M., \& Zujko, M.E. (2018). Endogenous non-enzymatic antioxidants in the human body, Advances in Medical Sciences, 63, 68-78.

Ndrepepa, G., Colleran, R., \& Kastrati, A. (2018). Gamma-glutamyl transferase and the risk of atherosclerosis and coronary heart disease, Clinica Chimica Acta, 476, 130-138.

Rønning, T.G., Aas, C.G., Støen, R., Bergh, K., Afset, J.E., Holte, M.S., \& Radtke, A. (2019). Investigation of an outbreak caused by antibiotic-susceptible Klebsiella oxytoca in a neonatal intensive care unit in Norway, Acta Paediatrica, 108, 76-82.

Rossoni, R.D., Fuchs, B.B., De Barros, P.P., Velloso, M.D.S., Jorge, A.O.C., Junqueira, J.C., \& Mylonakis, E. (2017). Lactobacillus paracasei modulates the immune system of Galleria mellonella and protects against Candida albicans infection. Plos One, 12, e0173332.

Sertçelik, M., Sugeçti, S., Büyükgüzel, E., Necefoğlu, H., \& Büyükgüzel, K. (2018). Toxicological and physiological effects of diaquabis (N, N-diethylnicotinamide-x N1) bis (4-formylbenzoato-x $\mathrm{O}$ ) cobalt (II) complex on Galleria mellonella L. Karaelmas Science and Engineering Journal, 8, 359-364.

Shaik, H.A., Mishra, A., Sehadová, H., \& Kodrík, D. (2020). Responses of sericotropin to toxic and pathogenic challenges: possible role in defense of the wax moth Galleria mellonella. Comparative Biochemistry and Physiology Part C: Toxicology \& Pharmacology, 227, 108633.

Singulani, J.L., Scorzoni, L., De Oliveira, H.C., Marcos, C.M., \& Assato, P.A. (2018). Fusco-Almeida, A.M. and Mendes-Giannini, M.J.S., Applications of invertebrate animal models to dimorphic fungal infections, Journal of Fungi, 4, 118.

SPSS (2006). User's manual, Version 15. SPSS, Chicago. IL.

Sugeçti, S., Büyükgüzel, E., \& Büyükgüzel, K. (2016). Laboratory assays of the effects of oxfendazole on biological parameters of Galleria mellonella (Lepidoptera: Pyralidae), Journal of Entomological Science, 51, 129-137.

Sugeçti, S. \& Büyükgüzel. K. (2018). Effects of oxfendazole on metabolic enzymes in hemolymph of Galleria mellonella L. (Lepidoptera: Pyralidae) larvae reared on artificial diet. Karaelmas Science and Engineering Journal, 8, 590-594.

Sugeçti, S. (2021a). Biochemical and immune responses of model organism Galleria mellonella after infection with Escherichia coli. Entomologia Experimentalis et Applicata, 169, 911-917.

Sugeçti, S. (2021b). Pathophysiological effects of Klebsiella pneumoniae infection on Galleria mellonella as an invertebrate model organism. Archives of Microbiology, 203, 3509-3517.

Tominaga, T. (2018). Rapid detection of Klebsiella pneumoniae, Klebsiella oxytoca, Raoultella ornithinolytica and other related bacteria in food by lateral-flow test strip immunoassays. Journal of Microbiological Methods, 147, 43-49.

Tsai, C.J.Y., Loh, J.M.S., \& Proft, T. (2016). Galleria mellonella infection models for the study of bacterial diseases and for antimicrobial drug testing. Virulence, 7, 214-229.

Wand, M.E., McCowen, J.W., Nugent, P.G., \& Sutton, J.M. (2013). Complex interactions of Klebsiella pneumoniae with the host immune system in a Galleria mellonella infection model. Journal of Medical Microbiology, 62, 1790-1798. 